Supplement of The Cryosphere, 12, 3177-3186, 2018

https://doi.org/10.5194/tc-12-3177-2018-supplement

(C) Author(s) 2018. This work is distributed under

the Creative Commons Attribution 4.0 License.

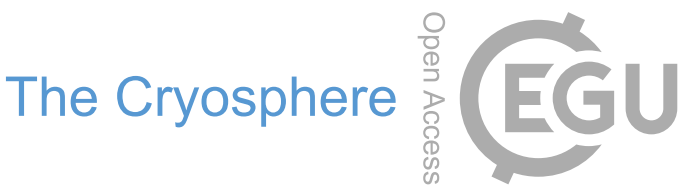

(c) (1)

Supplement of

\title{
Iron oxides in the cryoconite of glaciers on the Tibetan Plateau: abundance, speciation and implications
}

Zhiyuan Cong et al.

Correspondence to: Shichang Kang (shichang.kang@lzb.ac.cn)

The copyright of individual parts of the supplement might differ from the CC BY 4.0 License. 


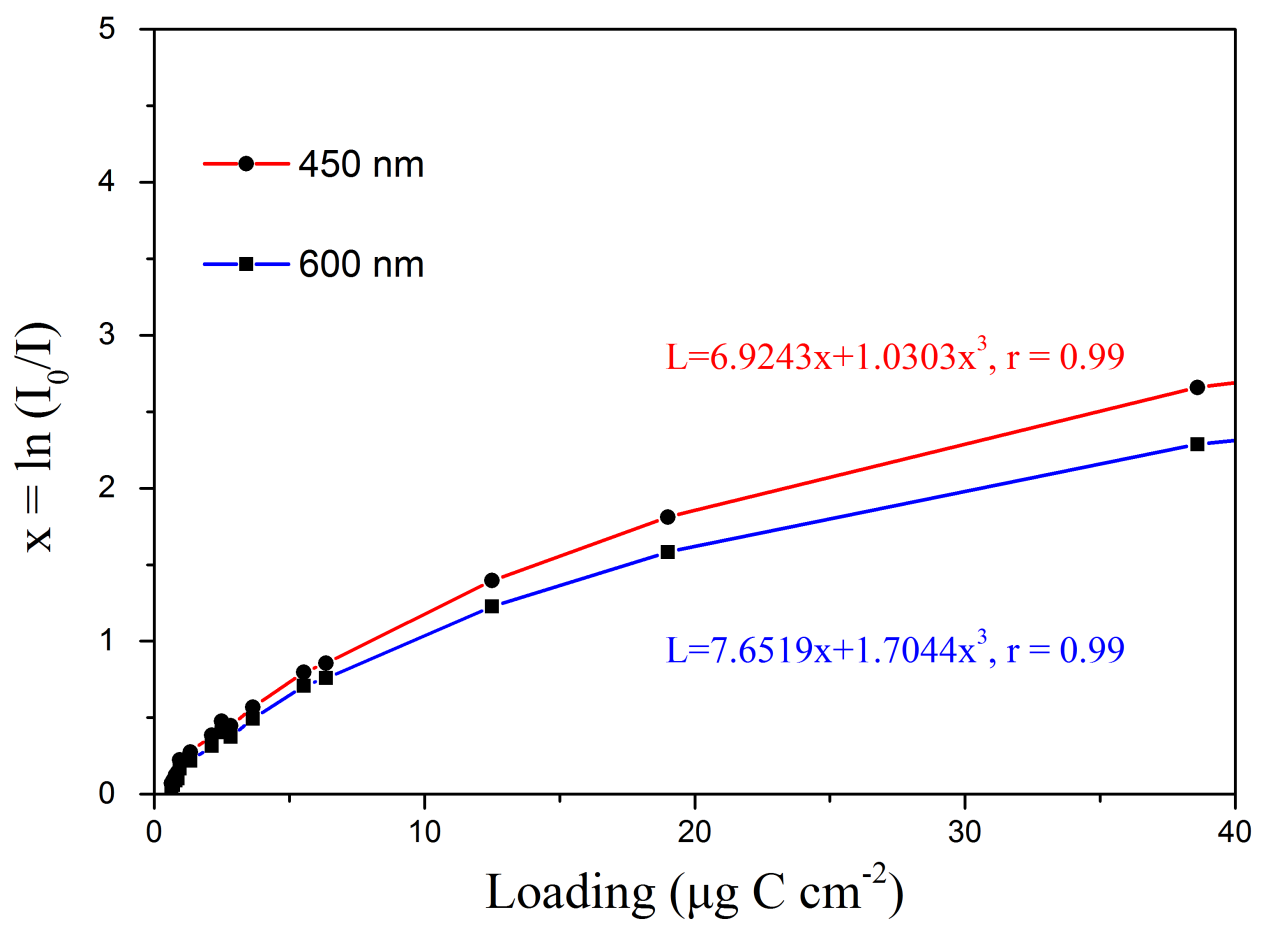

Figure S1. The calibration curve for $450 \mathrm{~nm}$ (red) and $600 \mathrm{~nm}$ (blue) against black carbon standards (fullerene soot). The solid curves were derived from best-fit of third-order polynomial between loading and attenuation, with the correlation coefficient (r) of 0.99 . 